\title{
Cough up your lungs
}

\section{A. J. Rammeloo' • N. A. Blom²}

Published online: 17 April 2018

(c) The Author(s) 2018

\section{Question}

After a frightening coughing episode, a 5-year-old boy with a congenital heart condition expectorated what is shown in the image sent by his father (Fig. 1). He had no fever or signs of chest infection. What is your diagnosis?

\section{Answer}

You will find the answer elsewhere in this issue.

Open Access This article is distributed under the terms of the Creative Commons Attribution 4.0 International License (http:// creativecommons.org/licenses/by/4.0/), which permits unrestricted use, distribution, and reproduction in any medium, provided you give appropriate credit to the original author(s) and the source, provide a link to the Creative Commons license, and indicate if changes were made.

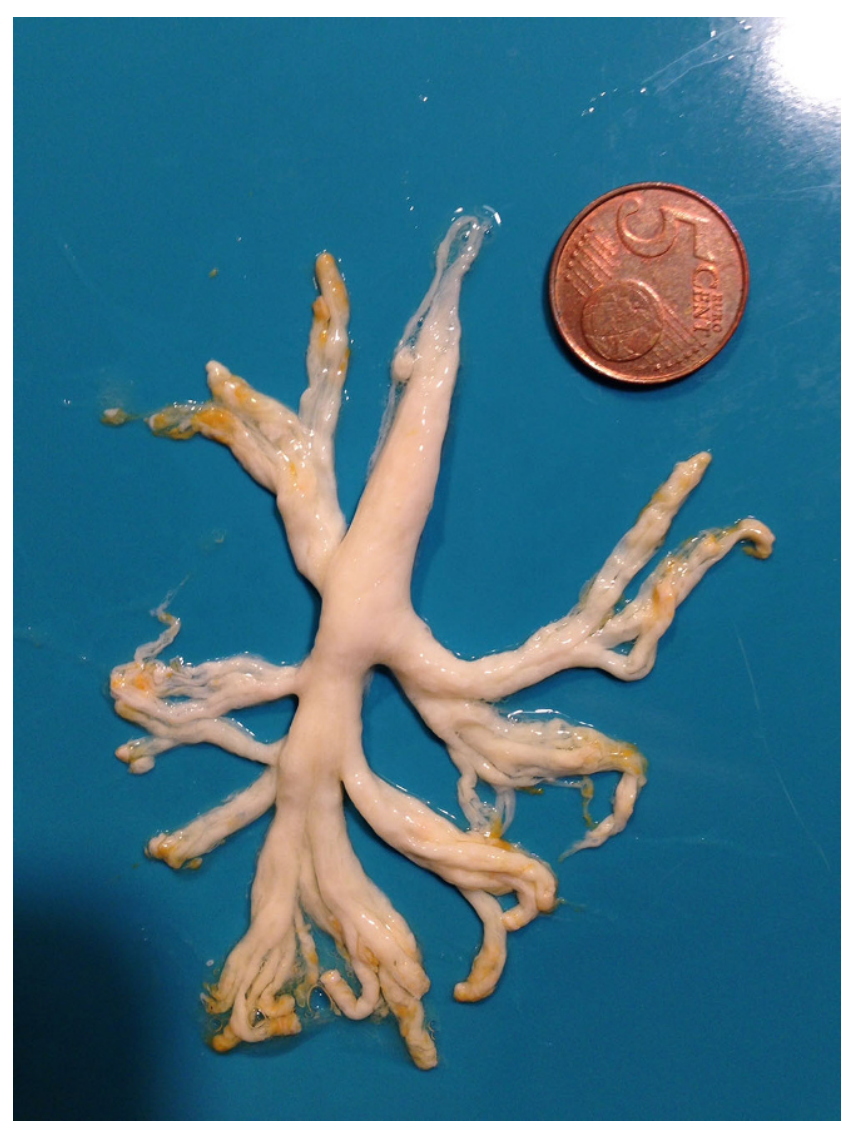

Fig. 1 A picture sent by the father showing a expectorated product with a $5 €$ Cent coin $(20 \mathrm{~mm})$ as a size reference

L. A. J. Rammeloo

1.rammeloo@vumc.nl

1 Department of Paediatric Cardiology, VU University Medical Center, Amsterdam, The Netherlands

2 Department of Paediatric Cardiology, Leiden University Medical Center, Leiden, The Netherlands 